\title{
Core and corona structure of mixed polymeric micelles
}

\author{
Ilja K. Voets, * Arie de Keizer, and Martien A. Cohen Stuart
}

Core and Corona Structure. ${ }^{1} \mathrm{H}$ NMR spectra of the individual polymers were recorded at $298 \mathrm{~K}$ on a Bruker AMX-400 spectrometer, operating at $400 \mathrm{MHz} .{ }^{1} \mathrm{H}$ NMR spectra of the micellar solutions were recorded at $298 \mathrm{~K}$ on a Bruker AMX-500 spectrometer, operating at $500 \mathrm{MHz}$, located at the Wageningen NMR Centre. For the 2D NOESY spectrum 976 experiments of 2048 data points were recorded, consisting of 16 scans per $T 1$ value, using standard Bruker software. The mixing time was varied in the range of $200-1000$ ms. The time domain data were multiplied with a phase-shifted sinesquare window. Phase-sensitive Fourier transformation, resulting in a data set of 1024 X 512 complex points, was followed by polynomial baseline corrections in both directions. The spectra obtained with different mixing times are essentially the same, but the contour plot from the mixing time of $200 \mathrm{~ms}$ is clearest (Figure S1). Tables S1 and S2 list all the intra- and intermolecular NOE interactions. 


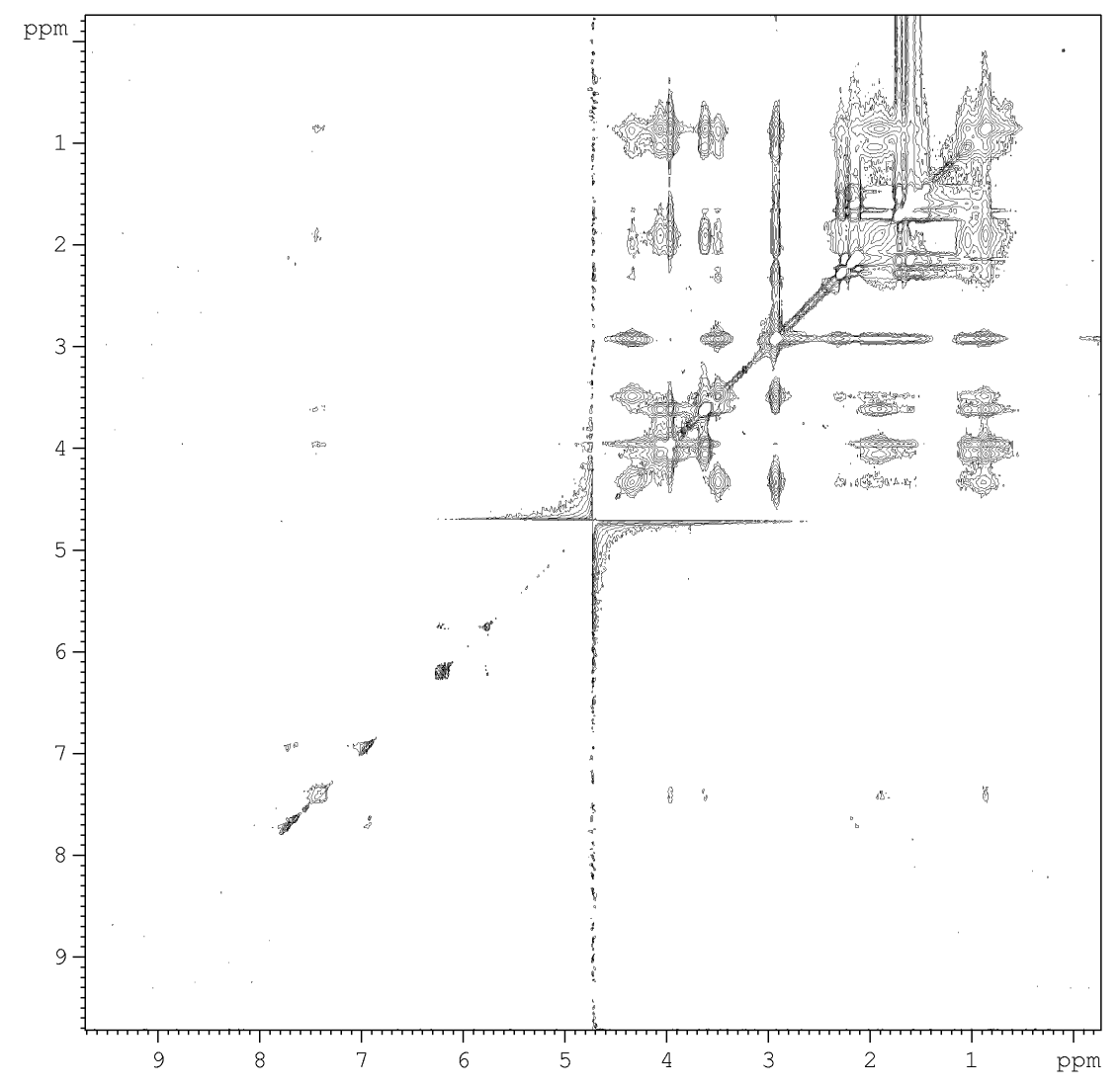

Figure S1. High resolution plot of the original 2D ${ }^{1} \mathrm{H}$ NMR NOESY contour plot of complex coacervate core micelles of PDMAEMA $45-b-\mathrm{PGMA}_{90}$ and $\mathrm{PAA}_{42}-b-\mathrm{PAAm}_{417}\left(1 \mathrm{mM} \mathrm{NaNO}_{3}, \mathrm{pH}=6.7\right.$, $\left.25^{\circ} \mathrm{C}, f_{+}=0.5, \mathrm{C}_{\mathrm{p}}=10 \mathrm{~g} / \mathrm{l}\right)$ in $\mathrm{D}_{2} \mathrm{O}$. 
Table S1. Intramolecular NOE interactions in complex coacervate core micelles of PDMAEMA $45-b-$ PGMA $_{90}$ and $\mathrm{PAA}_{42}-b-\mathrm{PAAm}_{417}\left(1 \mathrm{mM} \mathrm{NaNO}_{3}, \mathrm{pH}=6.7,25^{\circ} \mathrm{C}, f_{+}=0.5, \mathrm{C}_{\mathrm{p}}=10 \mathrm{~g} / \mathrm{l}\right)$ in $\mathrm{D}_{2} \mathrm{O}$. Numbers 1-14 correspond to protons as assigned in the main body of the text (see Figure 2,3).

Intramolecular NOE interactions

\begin{tabular}{lll}
\hline \hline Core/core & PAA & $11-12$ (i.e. all) \\
& PDMAEMA & $2-5^{\text {a } \text { (i.e. all) }}$ \\
\hline Core/corona & PAA/PAAm & $11-14$ (i.e. all) \\
& PDMAEMA/PGMA & 2,3 of PDMAEMA with 7-10; \\
& 4,5 of PDMAEMA with 7,10 but not with $8,9^{\mathrm{b}}$ \\
\hline Corona/corona & PAAm & $13-14$ (i.e. all) \\
& PGMA & $7-10^{\text {b }}$ (i.e. all)
\end{tabular}

${ }^{\mathrm{a}} \mathrm{NOE}$ interactions with proton 1 are not determined due to overlap with proton 6

${ }^{\mathrm{b}} \mathrm{NOE}$ interactions with proton 6 are not determined due to overlap with proton 1

Table S2. Intermolecular NOE interactions in complex coacervate core micelles of PDMAEMA $45-b-$ PGMA $_{90}$ and $\mathrm{PAA}_{42}-b-\mathrm{PAAm}_{417}\left(1 \mathrm{mM} \mathrm{NaNO}_{3}, \mathrm{pH}=6.7,25^{\circ} \mathrm{C}, f_{+}=0.5, \mathrm{C}_{\mathrm{p}}=10 \mathrm{~g} / \mathrm{l}\right)$ in $\mathrm{D}_{2} \mathrm{O}$. Numbers 1-14 correspond to protons as assigned in the main body of the text (see Figure 2,3).

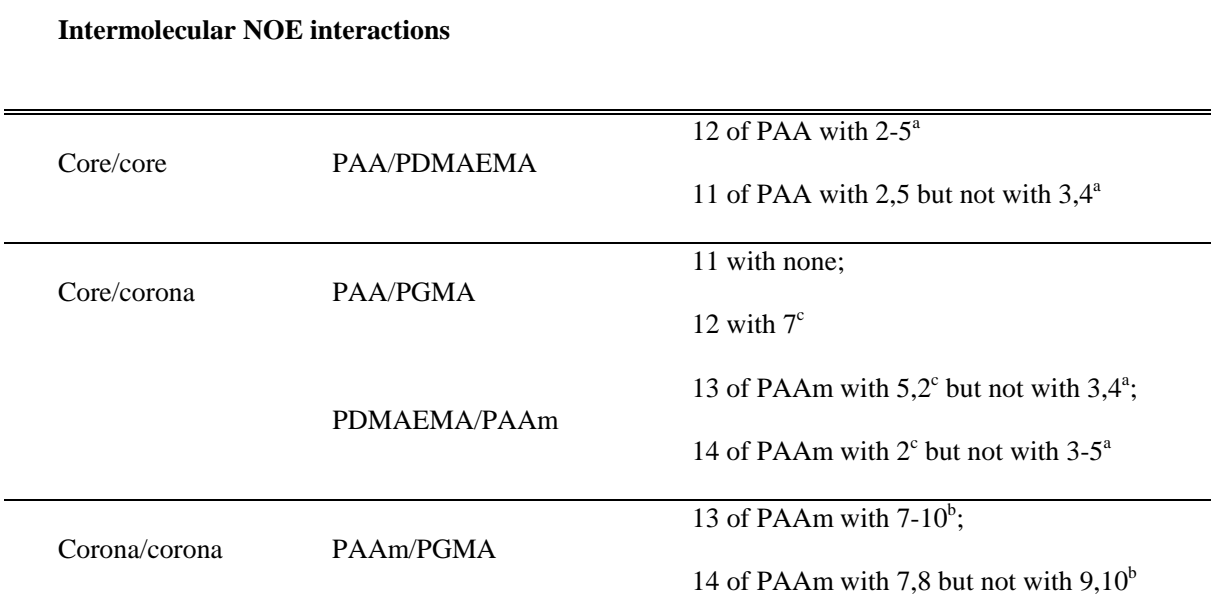

${ }^{\mathrm{a}} \mathrm{NOE}$ interactions with proton 1 are not determined due to overlap with proton 6

${ }^{\mathrm{b}} \mathrm{NOE}$ interactions with proton 6 are not determined due to overlap with proton 1

cmaybe a subject of some debate 